The research program of the Center for Economic Studies (CES) produces a wide range of theoretical and empirical economic analyses that serve to improve the statistical programs of the U.S. Bureau of the Census. Many of these analyses take the form of CES research papers. The papers are intended to make the results of CES research available to economists and other interested parities in order to encourage discussion and obtain suggestions for revision before publication. The papers are unofficial and have not undergone the review accorded official Census Bureau publications. The opinions and conclusions expressed in the papers are those of the authors and do not necessarily represent those of the U.S. Bureau of the Census. Republication in whole or part must be cleared with the authors.

\title{
HEALTH-RELATED RESEARCH USING CONFIDENTIAL U.S. CENSUS BUREAU DATA
}

by

Rosemary Hyson *

U.S. Census Bureau

and

Alice Zawacki *

U.S. Census Bureau

CES 08-21 August, 2008

\begin{abstract}
All CES discussion papers are screened to ensure that they do not disclose confidential information. Persons who wish to obtain a copy of the paper, submit comments about the paper, or obtain general information about the series should contact Sang V. Nguyen, Editor, Discussion Papers, Center for Economic Studies, Bureau of the Census, washington, DC 20233, (301-763-1882) or INTERNET address snguyen@ces.census.gov.
\end{abstract}




\begin{abstract}
Economic studies on health-related issues have the potential to benefit all Americans. The approaches for dealing with the growth of health care costs and health insurance coverage are ever changing and information is needed on their efficacy. Research on health-related topics has been conducted for about a decade at the Census Bureau's Center for Economic Studies and the Research Data Centers. This paper begins by describing the confidential business and demographic Census Bureau data products used in this research. The discussion continues with summaries of nearly 30 papers, including how this work has benefited the Census Bureau and its research findings. Some focus on data linkages and assessing data quality, while others address important questions in the employer, public, and individual insurance markets. This research could not have been accomplished with public-use data. The newly available data from the Agency for Healthcare Research and Quality and National Center for Health Statistics, as well as additional Census Bureau data now available in the Research Data Centers are also discussed.
\end{abstract}

* The authors thank B.K. Atrostic and others at the Census Bureau's Center for Economic Studies and Health and Surveys Training Branch for their reviews and editing assistance. Sanders Korenman, Kosali Simon and reviewers from the Agency for Healthcare Research and Quality and the National Center for Health Center for Health Statistics provided helpful comments. Finally, we thank the many authors of the papers discussed in this document for their feedback. 


\section{INTRODUCTION}

Economic studies on health-related issues have the potential to benefit all Americans. Decision makers, employers, and individuals are concerned about the growth of health care costs and health insurance coverage. Health care spending represented 16 percent of the gross domestic product in 2006, and health care reform is on the national agenda. ${ }^{1}$ The approaches for dealing with these concerns are ever changing and information is needed on their efficacy. For example, some new health plans, like health savings accounts coupled with high deductible plans, are available in the market. Recent changes in the employer and public provision of health care benefits for older individuals include unions assuming greater responsibility for retiree benefits and Medicare offering coverage for prescription drugs. Some discussions consider abandoning employersponsored insurance (ESI) and seeking alternatives to this system.

\subsection{Research to Date}

Research on health-related topics has been conducted for about a decade at the Center for Economic Studies (CES) and the Research Data Centers (RDCs). This paper begins by describing the confidential business and demographic U.S. Census Bureau data products used in this research. The discussion continues with summaries of how this work has benefited the Census Bureau and of its research findings. Nearly 30 papers are discussed. $^{2}$ Some focus on data linkages and assessing data quality, while others address important questions in the employer, public, and individual insurance markets. Contributions made by some of these papers can be seen in peer-reviewed journals such as Health Affairs (5), Journal of Public Economics, International Journal of Health Care Finance and Economics (2), Journal of Labor Economics, Health Services Research (2), Medical Care (2), and Inquiry (2).

This research could not have been accomplished with public-use data; for example, understanding the likely effect of proposals to expand health insurance coverage benefits from using more detailed measures of geography, income, diagnoses, and labor force activity than are available in public-use data. The Medical Expenditure Panel Survey-Insurance Component is the premier dataset on the main source of private coverage in this country, employer-sponsored insurance, and can be accessed only in secure Census Bureau facilities.

\subsection{New Partnerships and RDC Data}

The research questions addressed in the past 10 years focused primarily on health insurance markets, reflecting the data available at the time. New partnerships with the Agency for Healthcare Research and Quality (AHRQ) and the National Center for Health Statistics (NCHS) mean researchers at CES and the RDCs can explore many additional health-related topics in the future. This paper discusses the newly available AHRQ and NCHS data, as well as additional Census Bureau data now available in the RDCs. Researchers will be able to access these additional datasets with approval from the appropriate agency.

\footnotetext{
${ }^{1}$ Centers for Medicare and Medicaid Services, Office of the Actuary, National Health Statistics Group.

<www.cms.hhs.gov/NationalHealthExpendData/02_NationalHealthAccountsHistorical.asp>

${ }^{2}$ These represent a selection from the CES and RDC papers on health-related topics.
} 


\subsection{What We Have Learned from CES and RDC Research on Health-Related Issues}

\section{EMPLOYER-SPONSORED HEALTH INSURANCE (ESI)}

\section{Cost Sharing}

- Total premium costs decline when employers make a fixed dollar contribution towards all plans and offer additional plans. - Vistnes, Cooper, and Vistnes (2001)

- Simulations show that if employee contributions for single coverage were eliminated, up to 2.5 million more private sector employees would potentially enroll in ESI. - Cooper and Vistnes (2003)

- Most of the establishments that paid the full insurance premium were young, small, single units, with a relatively high paid workforce. - Zawacki and Taylor (2005)

- Through cost sharing arrangements, employers may be attempting to encourage their workers to enroll in family coverage through their spouse's plan.- Vistnes, Morrisey, and Jensen (2006)

Affordability

- $\quad$ ESI plans pay, on average, about 83 percent of medical bills. Small firms pay 18 percent more for coverage than large firms for the same financial protection. Gabel, McDevitt, Gandolfo, Pickreign, Hawkins, and Fahlman (2006)

- ESI tax exemptions, projected to be more than $\$ 200$ billion in 2006, are poorly targeted if they are intended to reduce the growing number of people without insurance or with public insurance. - Selden and Gray (2006)

Retiree Provisions

- The firm's financial performance and the availability of alternative insurance options play a small, but significant role in the proportion of the premium paid by employers for retiree health insurance. - Born and Zawacki (2006)

- Larger and older firms are more likely to offer retiree health insurance. Buchmueller, Johnson, and LoSasso (2006)

- New retirees' eligibility for employer-sponsored retiree health insurance declined roughly 5 percentage points between 2001 and 2004. - Eibner, Zawacki, and Zimmerman (2007) 


\section{EMPLOYER-SPONSORED HEALTH INSURANCE (cont'd)}

Institutional Framework

- Nondiscrimination rules reduce within-firm inequality in benefits and appear to increase use of benefits, such as health insurance. - Carrington, McCue, and Pierce (2002)

- State legislatures have enacted regulations to encourage more small employers to provide insurance, but RDC research suggests that the reforms resulted in a net decrease in coverage at small employers. - Simon (2005)

- Large employers reduced their offerings of health maintenance organization (HMO) plans and employees were less likely to choose HMOs from 1997 to 2003. - Cooper, Simon, and Vistnes (2006)

- Primarily due to federal Employee Retirement Income Security Act (ERISA) exemptions, state-level reforms aimed at expanding health benefits may have limited effect. - Buchmueller, Cooper, Jacobson, and Zuvekas (2007)

\section{PUBLIC INSURANCE PROGRAMS}

- Adjusted estimates suggest only minor underreporting of Medicaid coverage in California in the Survey of Income and Program Participation (SIPP)—85 percent of the total Medicaid coverage in California (Medi-Cal) population, and over 90 percent of children with Medi-Cal report eligibility in the SIPP. - Card, Hildreth, and Shore-Sheppard (2004)

- As more families had access to the State Children's Health Insurance Program (SCHIP) for their children, employers did not reduce offers of health insurance or coverage to dependents. - Buchmueller, Cooper, Simon, and Vistnes (2005)

- The Current Population Survey (CPS) uninsured rate for California is overestimated by 3 percentage points for adults and 8 percentage points for children. - Klerman, Ringel, and Roth (2005)

- Underreporting of Medi-Cal is likely due to a reluctance to report coverage by recipients. - Klerman and Ringel (2005)

\section{INDIVIDUAL INSURANCE MARKET}

- A subsidy of 50 percent would reduce the number of uninsured families by only about 4 to 8 percent. - Marquis, Buntin, Escarce, Kapur, and Yegian (2004)

- People in poor health at enrollment do pay higher prices than healthy people, but the differences are not large-on the order of 10 percent. - Marquis, Buntin, Escarce, Kapur, Louis, and Yegian (2006)

- Product choice is sensitive to price, while decreases in deductibles and out-ofpocket maximums will only modestly increase overall participation. - Marquis, Buntin, Escarce, and Kapur (2007)

- Premium subsidies for individual insurance would increase whole family coverage and reduce the number of partially uninsured families among those who purchase individual coverage, but their role would be small. - Kapur, Escarce, and Marquis (2007) 


\section{NEW AND EXISTING HEALTH-RELATED DATA AT CES AND THE RDCS}

Access to the confidential data on health insurance and health status at CES and the RDCs provides researchers with more detailed information. Such richness yields insights that could not be achieved with publicly available data. Although some of the RDC datasets have public-use equivalents, these often have to suppress, aggregate, or top-code measures for disclosure avoidance. In contrast, the detailed geographic information in RDC files enables researchers to examine topics such as how characteristics of local insurance markets, households, or public programs affect health insurance coverage. In other cases, the public-use files contain only a fraction of the total responses available in the RDC versions.

There are also some RDC datasets that have no public-use equivalents, so researchers can work with the microdata only through an approved project at a Census Bureau RDC. For example, for studying employers' decisions to offer health insurance, no publicly or privately available data can match the Medical Expenditure Panel Survey-Insurance Component (MEPS-IC) list sample's coverage of private sector employers in the United States or the number of years of data. The MEPS-IC list sample data are only available at CES and the RDCs.

RDC research also demonstrates how combining several sources of microdata can extend the depth and range of questions that can be examined. For example, access to more detailed geography allows researchers to add information on provision of health care in an area. Projects using RDC business data can combine information on employer health insurance plans and business outcomes from two different confidential RDC datasets. New partnerships with the Agency for Healthcare Research and Quality (AHRQ) and the National Center for Health Statistics (NCHS), and the addition of new Census Bureau data, further increase the range of research on heath-related topics that can be conducted through the RDCs.

\subsection{Census Bureau Data}

Census Bureau datasets containing information about health insurance used by CES and Census Bureau RDC researchers include the list sample MEPS-IC, the Current Population Survey Annual Social and Economic Supplement (CPS ASEC), and the Survey of Income and Program Participation (SIPP). These three datasets are discussed below. The American Community Survey (ACS), which began collecting information on health insurance in January 2008, is also available to RDC researchers.

To date, much of the research at CES and the RDCs has focused on the topic of health insurance simply because the Census Bureau collects more information on this topic than on other health-related issues. However, some measures of the incidence and extent of disability are available in the SIPP and CPS, as well as the decennial census and the ACS. A general measure of self-reported health status is also available in the CPS. Information on medical expenses, general health status, utilization of health care services, child height and weight, long-term care, and home health care are included in various SIPP topical module datasets available at the RDCs. ${ }^{3}$

\footnotetext{
${ }^{3}$ Detailed information on which panels and topical modules cover health topics can be found on the SIPP Web site <www.bls.census.gov/sipp/top_mod/top_mods_chart.html>.
} 


\subsection{Business Data: MEPS Insurance Component}

2007 marked the 10-year anniversary of annual data collection for the MEPS-IC and the successful long-term institutional partnership between the Census Bureau and the AHRQ. ${ }^{4}$ Under sponsorship from AHRQ, the Census Bureau collects information on employer-sponsored health insurance in the MEPS-IC list sample survey. Together, AHRQ and the Census Bureau develop and provide the premier data source for the study of the dynamic employer-sponsored insurance system.

The MEPS-IC list sample uses the Census Bureau's Business Register as its sampling frame and thus is nationally representative of private sector employers with one or more employees in the United States. ${ }^{5}$ Approximately 25,000-35,000 establishments are included in the repeated cross-sectional sample every year. ${ }^{6}$ This large sample size, combined with the Census Bureau's ability to achieve a high response rate, contributes to making the MEPS-IC the leading source of data on employer-sponsored health insurance.

MEPS-IC collects detailed information from businesses on whether employees are offered health insurance and, if so, details on the type and cost of coverage for as many as four plans. Surveyed establishments are asked to report information on provider arrangements (exclusive, fee-for-service, mixed), gate keeping, premiums for single and family coverage (including employer and employee shares), deductibles, copayments, and coinsurance. Retiree health insurance information is collected at the firm level, but the data file includes a retiree weight that permits establishment-level analyses of retiree health insurance issues. ${ }^{7}$ Information on non-health fringe benefits at the establishment level (vacation, sick leave, and pensions) is also collected, along with general information about the employer and its workforce.

\subsection{Household Data}

The CPS and SIPP are household surveys that capture information on whether individuals in a household are covered by insurance and the type of insurance (individual, employer-sponsored, and a range of specific public insurance plans). Both surveys are frequently used to estimate the number and proportion of insured and uninsured among the noninstitutionalized population. ${ }^{8}$ These datasets also contain background information on households and individuals, such as income, labor market outcomes, demographics, household structure, and disability status. The versions of the CPS and SIPP available through the Census Bureau RDCs have more detailed levels of geography that enable researchers to merge external data to enhance analyses of health insurance coverage and reported disability status. A number of disclosure-avoidance protections on the publicuse files are removed, such as the top-coding of income.

The CPS began asking questions about health insurance in 1980 in the March Income Supplement and asks about coverage at any time during the previous calendar

\footnotetext{
${ }^{4}$ The MEPS-IC list data were first collected in 1997 for the calendar year 1996.

${ }^{5}$ The MEPS-IC sample also includes establishments selected from the Census of Governments to collect information from state and local governments on health insurance offerings. These data are not confidential.

${ }^{6}$ Survey instruments, methodology reports, publications, and summary data tables for the MEPS-IC can be found at $<$ www.meps.ahrq.gov>.

${ }^{7}$ An establishment is a single physical location where business is conducted. A firm is comprised of all the establishments that operate under the ownership or control of a single operation.

${ }^{8}$ For more information on health insurance data collected in the CPS and SIPP, see $<$ www.census.gov/hhes/www/hlthins/overview.html>.
} 
year. ${ }^{9}$ These data provide estimates of the uninsured and insured populations at both the state and national levels and are the official source of data used to allocate funding to states for the State Children's Health Insurance Program (SCHIP).

The SIPP is a longitudinal household survey that has been collecting data on health insurance coverage and disability since its inception in 1984. SIPP questions capture dynamic aspects of coverage-how long someone has or does not have coverage and changes between types of coverage. Preparations are currently underway for the 2008 SIPP panel, which is scheduled to begin in September 2008, and work is continuing to release the remaining data collected as part of the 2004 panel.

The decennial census datasets available at RDCs include 100 percent of the survey responses rather than the 1 percent or 5 percent available through the Public Use Microdata Sample Files (PUMS). The larger number of responses can aid analyses of events affecting smaller populations or narrow demographic groups. Although limited in nature, the disability status information is increasingly being used for projects at the RDCs. For example, access to the RDC versions of the decennial census data enabled one team of researchers to analyze how survey mode and interviewer error affected disability reporting. Another team used information on date of birth to analyze the impact of the Vietnam draft on disability status — see the summary in Text Box 1. This study could not have been done outside the RDC. The study required access to information that is not available on the PUMS data and the much larger number of observations available to RDC researchers.

\subsection{Additional Census Bureau Data Now Available at the RDCs}

The National Longitudinal Mortality Survey (NLMS) constructed by the Census Bureau became available through the RDCs in 2007. ${ }^{10}$ The NLMS is a research database that was constructed for analyzing variation in mortality by socioeconomic and demographic factors. The NLMS data were created by matching vital statistics records with a subset of 1980 Decennial Census respondents and respondents to the CPS ASEC (March). The version of the NLMS available to RDC researchers corresponds to publicuse NLMS Release 2 but with geographic detail.

\subsection{AHRQ and NCHS RDC Data Now Available at Census Bureau RDCs}

In 2007, CES-initiated agreements between the Census Bureau and AHRQ and NCHS enabled researchers to apply to AHRQ and NCHS to use these agencies' confidential RDC data for projects conducted at Census Bureau RDCs. ${ }^{11}$ Projects requesting NCHS and AHRQ RDC data go through the proposal process of each agency rather than that of CES and the Census Bureau. Similar to many of the Census Bureau RDC datasets, the AHRQ and NCHS RDC data give researchers the ability to control for geographic factors that affect health risks, status, behaviors, and outcomes to a greater

\footnotetext{
${ }^{9}$ Health insurance coverage is considered underreported in the CPS; compared with other national surveys, CPS estimates of the uninsured more closely approximate the number of individuals uninsured at a specific point in time than the number uninsured for the entire year. See DeNavas-Walt et al. (2007).

${ }^{10}$ See <www.census.gov/nlms/index.html>.

${ }^{11}$ For more information on NCHS RDC data and proposals, see <www.cdc.gov/nchs/r\&d/rdc.htm>; for AHRQ RDC data and proposals, see <www.meps.ahrq.gov/mepsweb/index.jsp>.
} 


\section{Text Box 1}

\section{Data Spotlight: RDC Confidential Decennial Census Data}

Recent work by Angrist and Chen (2007) highlights use of confidential RDC decennial census data to examine the long-term effect of the Vietnam draft on health status and labor market outcomes. The disability status and receipt of disability income data in the 2000 Decennial Census are important for this analysis. The RDC data on date of birth, however, enabled researchers to determine how likely males born from 1948-1952 were to have been drafted for Vietnam service. The random assignment of males born from 1948-1952 to Vietnam service via the draft lottery is used to minimize selection bias into military service. This identification strategy would not be possible without the confidential data available at the RDCs. The larger sample sizes of males with Vietnam-era service in the RDC data also allowed the researchers to calculate more precise estimates of any effects.

The researchers find no effect of the Vietnam draft on the likelihood of reporting a work disability, for both Whites and non-Whites. However, the researchers find that among Whites, Vietnam draftees were more likely to be receiving disability income in 2000. The effects on disability-related income variables for non-Whites are roughly double those for Whites but considerably less precise. The research results also show that service increased disability income only from programs specific to veterans, not Social Security Supplemental Income or Disability Income. The authors interpret this as evidence that health consequences of the Vietnam draft did not reduce veterans' earnings. The researchers also found no impact of service on work-related disability, labor supply, or work history.

extent than with the public-use data. The confidential RDC data also offer information that must be suppressed, top-coded, or aggregated on public-use files for disclosure avoidance. Certain NCHS and AHRQ datasets available through the RDCs have no public-use equivalents. Listings of the AHRQ and NCHS data currently available to researchers at Census Bureau RDCs are given in Text Boxes 2-4. Extracts of the restricted data are created by NCHS and AHRQ based on each approved project's scope and made available to the approved project researchers at a Census Bureau RDC.

AHRQ RDC Data. Data from AHRQ's RDC program currently available through Census Bureau RDCs include various components of the Medical Expenditure Panel Survey (MEPS). Researchers can apply to use the MEPS Household Component (MEPS-HC). MEPS-HC has collected data since 1996 on health insurance coverage and costs, socioeconomic and demographic characteristics, health status and behaviors, and healthcare access and utilization. While public-use files for the MEPS-HC can be downloaded from the Internet, the RDC versions of these files can be used in conjunction 
with other confidential RDC data. The MEPS Two-Year, Two-Panel file matches individuals across the first and second year of the MEPS-HC and can also be used at the AHRQ and Census Bureau RDCs. The RDC versions also provide information not available on the public-use file, such as estimated federal and state marginal tax rates, as well as detailed diagnosis codes. ${ }^{12}$

The MEPS Medical Provider Component includes charge and payment data from hospitals, physicians, home health care providers, and pharmacies that can be added to household reports of health care expenditures found in the MEPS-HC. The billing data also include procedure codes (CPT4) and diagnosis codes for medical visits and stays and NDC prescription codes. While some components of the provider information are available to be linked to the public-use MEPS-HC, much more detail is available in the AHRQ RDC version.

Other AHRQ RDC files now available through Census Bureau RDCs have no public-use version. The MEPS Household Component-Insurance Component linked file (available for 1996-1999 and 2001) surveyed the employers of MEPS-HC respondents to collect information on health insurance offerings in the workplace. Such linked data give researchers the opportunity to study workers' insurance options and selected coverage more thoroughly by using data from both the employer and the household. The 1996 MEPS Nursing Home Component collected information on characteristics of the facility and residents, including health status, residence history, and expenditures, and is only available at the AHRQ and Census Bureau RDCs.

Geographic contextual information can be merged in by AHRQ at the state, county, census tract, or block group level and made available for use in RDC projects. AHRQ will also merge county-specific data from the Area Resource File (ARF) to the MEPS-HC data. The ARF contains information on health care providers, health status, economic activity, health training programs, and socioeconomic and environmental characteristics.

NCHS RDC Data. Many NCHS datasets are available for use at Census Bureau RDCs through the NCHS RDC program. The National Health Interview Survey (NHIS) includes information on detailed health characteristics of individuals, health care access and utilization, health insurance, and socioeconomic and demographic characteristics. NHIS includes three measures of uninsured status: current, intermittent (uninsured at least part of the prior year), and long term (uninsured for more than a year). NHIS data are available starting in 1969. Compared to the public-use file, the RDC data include more information on income, earnings, and the nature and timing of health events in addition to exact age, geography of residence, and place of birth.

The National Health and Nutrition Examination Survey (NHANES) has been collected since 1971 and includes information on socioeconomic and demographic characteristics, risk factors, behaviors, and directly measured data on health status and outcomes. Through the RDCs, NHANES users can add information by state and county geography.

The National Vital Statistics System (NVSS) data are also available through the NCHS RDC program. This group of datasets include birth and death records as well as

\footnotetext{
${ }^{12}$ Federal and state marginal tax rates are estimated using the National Bureau of Economic Research's TAXSIM package.
} 
the National Survey of Family Growth (NSFG), which tracks reproductive health. The RDC data on natality and mortality provide more precise dates and geography that are no longer available in the public-use file. The NSFG RDC data include geographic contextual details that range from socioeconomic characteristics of the community to crime and family planning services' availability. Use of NVSS datasets at the RDCs facilitates studies of life expectancy, causes of death, pregnancy and birth outcomes, prenatal care, and nonmarital births.

NCHS RDC data include surveys of various types of providers, such as nursing homes, hospitals, home and hospice care, and ambulatory care facilities, as part of the National Health Care Surveys. NCHS RDC data also offer versions of several surveys, including the NHIS and NHANES, that are linked to administrative data on mortality, health care costs and utilization records from Medicare, and retirement and disability data from the Social Security Administration.

\section{Text Box 2}

\section{AHRQ Data Available Through Census Bureau RDCs}

Project-specific extracts can be created from the following Agency for Healthcare Research and Quality (AHRQ) Medical Expenditure Panel Survey datasets for AHRQapproved projects at Census Bureau RDCs:

a. Household Component-Insurance Component linked file (1996-1999, 2001)

b. Nursing Home Component (1996)

c. Medical Provider Component (except directly identifiable data)

d. Two-Year, Two-Panel Files

e. Area Resource File county-level data linked to MEPS-HC

f. MEPS-HC Public-Use Files linked to confidential variables

Researchers interested in using these data should contact AHRQ directly through its Web site <www.meps.ahrq.gov/mepsweb/data_stats/onsite_datacenter.jsp $>$. 


\section{Text Box 3}

\section{NCHS Data Available Through Census Bureau RDCs}

Project-specific extracts can be created from the following National Center for Health Statistics (NCHS) datasets for NCHS-approved projects at Census Bureau RDCs:

a. National Health and Nutrition Examination Survey I, II, and III

b. National Ambulatory Medical Care Survey

c. National Hospital Ambulatory Medical Care Survey

d. National Survey of Ambulatory Surgery

e. National Hospital Discharge Survey

f. National Nursing Home Survey

g. National Home and Hospice Care Survey

h. National Employer Health Insurance Survey

i. National Health Provider Inventory

j. National Health Interview Survey 1967-2005

k. National Immunization Survey

l. Longitudinal Study on Aging

m. National Survey of Family Growth

n. State and Local Area Integrated Telephone Survey

1. Health

2. Child Well-Being and Welfare, 1997

3. National Survey of Early Childhood Health

4. National Survey of Children With Special Health Care Needs

5. National Survey of Children's Health

6. National Asthma Survey

7. National Survey of Children With Special Health Care Needs

o. Vital Statistics

1. Birth

2. Mortality

3. Marriages and Divorces

4. Fetal Death

5. National Death Index

Researchers interested in using these data should contact NCHS directly through its Web site <www.cdc.gov/nchs/r\&d/rdc.htmthrough>. 


\section{Text Box 4}

\section{NCHS Data Linked to Other Agency Data Available Through Census Bureau RDCs}

Project-specific extracts can be created from the following National Center for Health Statistics (NCHS) datasets linked with data from other agencies for NCHS-approved projects at Census Bureau RDCs:

a. National Health and Nutrition Examination Survey II with Medicare utilization and expenditure data 1991-2000

b. National Health and Nutrition Examination Survey III with mortality data 1988-2000

c. National Health and Nutrition Examination Survey III with Medicare enrollment and claims data (CMS-1991-2000)

d. National Health and Nutrition Examination Survey III with Social Security Administration retirement, survivors, and disability insurance data 1974-2003

e. National Health and Nutrition Examination Survey III with Social Security Administration Supplemental Security Income data 1974-2003

f. Longitudinal Study of Aging II with mortality data 1994-2002

g. Longitudinal Study of Aging II with Medicare enrollment and claims data 1991-2000

h. Longitudinal Study of Aging II with Social Security Administration retirement, survivors, and disability insurance data 1962-2003

i. Longitudinal Study of Aging II with Social Security Administration Supplemental Security Income data 1974-2003

j. 1985 National Nursing Home Survey with mortality data 1985-2002

k. 1985 National Nursing Home Survey with Social Security Administration retirement, survivors, and disability insurance data 1962-2003

l. 1985 National Nursing Home Survey with Social Security Administration Supplemental Security Income data 1974-2003

Researchers interested in using these data should contact NCHS directly through its Web site $<$ www.cdc.gov/nchs/r\&d/rdc.htm > 


\section{HOW HEALTH-RELATED RESEARCH HAS BENEFITED THE CENSUS BUREAU}

The primary purpose of encouraging external researchers to use confidential Census Bureau data is to generate information that will benefit a Census Bureau program, statistic, or survey. CES and RDC projects benefit the Census Bureau in many ways. ${ }^{13}$ This section highlights projects that enhanced or improved the quality and usefulness of Census Bureau datasets by documenting the content and quality of a survey for its use in studying particular topics, linking data to create richer datasets to better answer important questions, or evaluating the impact of improvements to specific questions on a survey. However, it should be noted that most of the projects cited in this section and throughout this paper produced additional benefits not discussed here.

\subsection{Documenting Data}

The increasing cost of health care and growing share of the population aged 55 and older, make it important to know about health insurance available to older individuals. Employer-sponsored insurance for retirees is often the sole source of coverage for retirees not yet eligible for Medicare and provides supplemental coverage for Medicare-eligible retirees. As part of a larger research project, Zawacki (2006) documents how the MEPS-IC data can be used to study employer-sponsored retiree health insurance (RHI). This paper describes the RHI measures collected on plans offered to those already retired-Medicareeligible (aged 65 and older) and early retirees (under age 65) —and to new retirees, including eligibility, enrollment, premiums, and cost sharing. The author also presents preliminary estimates of trends in RHI provision. Changes have been made in the MEPS-IC RHI questions since 1996 to improve data collection and to respond to emerging RHI issues. Zawacki provides suggestions for estimating data elements that are not available every survey year. The author also describes item nonresponse issues and their possible role in explaining unexpected patterns in the estimates. Inconsistencies between imputed values of RHI offers and premium/enrollment information are also discussed, but the author points out that less than 5 percent of establishments are affected.

\subsection{Linkages}

One of the advantages of the MEPS-IC being based on the same sampling frame as most of the Census Bureau's business surveys is that MEPS-IC data can be linked with additional information about establishments and firms. McCue and Zawacki (2006) describe the results from matching 1997 MEPS-IC private list sample data to the 1997 Economic Census. The match between the MEPS-IC data and the economic census was of high quality, and, more significantly, there was no evidence that the matched establishments were biased towards offering or not offering health insurance benefits. The combined data on health insurance plan offers and business characteristics can be used to examine factors underlying employer offers of health insurance and the role that such benefits play in compensating workers and determining productivity. McCue and Zawacki's analysis finds that firms offering health insurance to employees had 25 percent greater labor productivity and 32 percent higher pay when other characteristics of the establishments were held constant. Such

\footnotetext{
${ }^{13}$ All RDC projects must propose benefits to the Census Bureau under at least one of several criteria. See $<$ www.ces.census.gov>.
} 
analyses have the potential to provide important insights as employers consider ways to restructure health insurance offers to meet cost pressures.

The MEPS-IC list sample is nationally representative of private sector employers. Similar information collected from the employers of individuals in the Medical Expenditure Panel Survey-Household Component (MEPS-HC) is called the MEPS-IC household sample. ${ }^{14}$ Cooper, Hagy, and Vistnes (1999) compare employer size and multiunit status in the two samples. ${ }^{15}$ The employer characteristics were obtained by linking each dataset to the Census Bureau's Business Register for 1996. Many more employers in the MEPS-IC household sample are multiunit and are larger employers - over 46 percent of the MEPS-IC household sample establishments have at least 50 employees, while only 17 percent of MEPS-IC list sample employers are in this size class. This project benefited the Census Bureau and AHRQ by comparing the two datasets on employer-sponsored health insurance (ESI). It assessed how representative the employer information derived from the MEPS-IC household sample is and documented how and why the two MEPS-IC samples differ.

Decressin, McCue, and Stinson (2003) describe the creation of a new dataset that combines administrative data on health benefits and other tax-advantaged benefits from the Internal Revenue Service (IRS) Form 5500 and the Census Bureau's Business Register. The combined data include benefits information for most businesses in the Business Register. The result is a larger, richer dataset than what most surveys can offer for analyzing how benefit provision varies with industry, size, and other firm characteristics, as well as business and worker outcomes. Several years of Form 5500 data are available and thus, can be used to examine how benefits change in response to changes in the insurance market, firm and businesses circumstances, and labor markets. However, while most large employers offering health benefits must file Form 5500, an important limitation to the data is that most firms with small health plans (less than 100 participants, unfunded or fully insured) are not required to file Form 5500. Also, when the plan sponsor is not an employer (e.g., trade union plans), there is no way to match up the benefits data with participants' employers. For large firms, the match was successful. Subsequent research using this combined data linked to the Longitudinal Employer Household Dynamics data has examined whether firms benefit in terms of productivity, worker turnover, employment growth, and survival by offering health and other benefits (Decressin et al., 2005; Decressin et al., forthcoming).

\subsection{Assessing Data Quality}

A project by Houtenville and Erickson (2007) aimed to help improve measurement of the disabled population. Accurate measures of the numbers of people with various disabilities are critical for planning to assure that services, such as mass transit, Medicare, and Medicaid, are adequate to serve the disabled population. However, the factors defining a disability are complex, which makes disabilities difficult to precisely identify with a limited number of survey questions. The researchers focus on measures of employment and "gooutside-the-home” (mobility) disabilities in the 2000 Decennial Census and 2000-2005 ACS. Prior work by Census Bureau staff (Stern, 2003; Stern \& Brault, 2005) indicated that

\footnotetext{
${ }^{14}$ An important difference between the two MEPS-IC sources is that only 60 percent of respondents to the MEPS-HC gave permission for MEPS to survey their employers. Studies based on the MEPS-IC household sample therefore may not be nationally representative.

${ }^{15}$ Multiunit establishments are single locations belonging to a business operating in more than one location.
} 
respondent and interviewer errors related to the layout of this disability question resulted in unexpectedly high rates for these disabilities. Houtenville and Erickson confirm these earlier results. To better understand why respondents report with error, the researchers use other data elements, such as disability income and nonproblematic disability measures, to identify respondents who erroneously reported a work disability. The size of this group declines in accordance with the improvements in the survey and the use of more experienced enumerators. The researchers plan to analyze whether particular characteristics of this group, such as age or education, are associated with a greater likelihood of respondent error.

\section{SOURCES OF HEALTH INSURANCE COVERAGE}

Studies at CES and the RDCs have examined many of the trends and interactions in the employer-sponsored, public, and individual health insurance markets using Census Bureau data. Figure 1 shows the percent coverage from each of these sources for each age segment of the population in 2006 using data from the Current Population Survey (CPS). ${ }^{16,17}$ The figure shows that individuals of all ages rely upon coverage from the employer-sponsored system. This reliance wanes from 60 to 67 percent for younger people to 36 percent for people 65 years of age or older, when Medicare becomes the primary insurer. Another public source of coverage, Medicaid provides health insurance to 27 percent of children. Figure 1 also shows that 5 to 10 percent of people under the age of 65 and almost 28 percent of people 65 years of age or older purchase coverage on their own through the individual (direct) market, either as their only source of insurance or as supplemental coverage. Finally, many individuals are uninsured. Researchers at CES and the RDCs have used both business and demographic data from the Census Bureau separately, linked to external data sources and in unique combination with one another, to examine health-related issues in each of these markets. The remainder of the paper summarizes studies conducted at CES and the RDCs that examine topics in these three markets.

\section{EMPLOYER-SPONSORED HEALTH INSURANCE}

\subsection{Cost Sharing}

A number of researchers from CES and Census Bureau RDCs have examined contributions made by employers and workers towards the premium for ESI. Each of the papers described here used confidential RDC MEPS-IC data, which provide benefits over other ESI data because of their more representative sampling and annual collection schedule. Rising health care costs contribute to higher total premiums for health insurance. RDC research shows how increasing competition among plans may lower these premiums. New estimates from other studies show that employee contributions towards premiums influence employees' enrollment decisions, and these contributions may be affected by characteristics of their employer, workforce, and local markets.

\footnotetext{
${ }^{16}$ CPS estimates of health insurance coverage are considered underreported. See DeNavas-Walt et al. (2007).

${ }^{17}$ Individuals may receive coverage from more than one source; therefore, totals within each age category may exceed 100 percent. These figures come from the basic CPS sample of the resident civilian noninstitutionalized population and do not include people in institutions, such as nursing homes and long-term care hospitals.
} 
While rising premiums may challenge employers' budgets for employee compensation, many employers offering ESI offer plans without requiring any employee contributions towards its premium. Further, Zawacki and Taylor (2005) find little change in the percent of establishments offering insurance that pays 100 percent of the premium regardless of the number of plans offered. Estimates are based on the MEPS-IC data from 1997-2001, as seen in Figure 2. Most of the establishments that paid the full premium were young, small, single units, with a relatively high paid workforce. The authors note that because many of these establishments are single units and small in terms of the number of people employed, the health benefit decisions made by these employers impact a small percentage of the workforce.

How do workers' out-of-pocket premiums (or their absence) affect their decision to enroll in ESI? Cooper and Vistnes (2003) address this question using 1997-1999 MEPS-IC data on establishments offering ESI. They find that higher employee contributions for single coverage are associated with lower enrollment. The researchers simulate what enrollment would be if employers contribute the full premium cost for single coverage. If employee contributions for single coverage in 1999 fell to zero in establishments that had required a positive employee contribution, enrollment in these establishments would have increased by approximately 6 percentage points. The data do not allow the researchers to determine whether this would be supplemental coverage or if this represents newly insured individuals. The simulations show that if employee contributions for single coverage were eliminated, however, 2.5 million more private sector employees would potentially enroll in ESI.

Given concerns about rising health insurance costs, policymakers and researchers have been interested in studying ways to control these costs. Economic theory suggests that increased competition among health plans can help lower these premiums. Vistnes et al. (2001) investigate the importance of competition among plans at two stages in the ESI market. The researchers first look at the competition among plans for selection by employers and then at competition among plans offered by the employer for employee enrollment. Based on the 1996 MEPS-IC, they find that total premiums decrease when employers make a fixed dollar contribution towards all plans and offer additional plans. This study shows that when employers contribute the full premium cost for all offered plans and increase their number of offered plans, total premiums actually rise.

Employers may also use their premium contributions along with worker preferences to strategically sort employees into different health plan options. Through cost-sharing arrangements, employers may be attempting to financially motivate their workers to enroll in family coverage through their spouse's plan rather than through their own employer. Using the 1997-2001 MEPS-IC and the Census Bureau's PUMS for 2000, Vistnes et al. (2006) find that the marginal employee premium contribution for family coverage (the additional premium contribution for family coverage, over and above that for single coverage) is higher when more women are in the workforce but only in markets with a higher proportion of dual-earner households. These findings reveal that employers designing their cost-sharing arrangements consider both the characteristics of their workforce and the local labor market. 


\subsection{Affordability}

Rising premiums and out-of-pocket medical costs associated with health insurance plans affect the affordability of ESI. Some researchers have used Census Bureau data to study the financial protection provided by health plans offered in the workplace and subsidies for ESI. The studies described here have enhanced Census Bureau data by combining the restricted-use MEPS-IC and the MEPS-HC to create datasets that contain both business data on employers and demographic data on individuals. The RDC researchers find that ESI plans with exclusive providers pay a higher percentage of a medical bill, and ESI subsidies may not be the best approach for encouraging ESI coverage of the uninsured or those on public insurance.

What financial protection against high out-of-pocket medical costs do ESI plans offer workers? To address this question, Gabel et al. (2006) calculate actuarial values (the percentage of the medical bill the health plan would pay, on average, for a standardized population) and quality-adjusted premiums. In the latter measure, the premiums are adjusted for the quality of the financial protection the plan provides to the employee and is basically the premium divided by the actuarial value. These measures are developed using the 2002 MEPS-IC and 2000 MEPS-HC along with other data sources (including 2002 National Health Expenditure Accounts). According to the study, the average actuarial value for an ESI plan is about 83 percent; actuarial values are determined primarily by the plan type rather than by firm size, industry, or workers' wages. Holding all other factors constant, a health maintenance organization's (HMO) plan had an actuarial value almost 14 percentage points higher than an indemnity plan. Quality-adjusted premiums, on the other hand, were strongly determined by firm size. Smaller firms (1 to 9 employees) faced adjusted premiums 18 percent higher than larger firms (1,000 or more employees).

CES and RDC research on the value and out-of-pocket costs of health plans offered to workers point to the affordability of ESI. For many individuals who are uninsured or receiving public assistance, the cost of ESI may be too great. Subsidies are intended to make ESI more affordable. Selden and Gray (2006) examine subsidies for ESI (exemptions from federal and state income taxes, social security, and Medicare taxes), and find these exemptions are poorly targeted if they are intended to stop the growing number of people without insurance or with public insurance. The authors statistically match a synthetic workforce created using pooled data from the 2000-2002 MEPS-HC with establishments in the 2002 MEPS-IC sample. This methodology helps maintain correlations between employer and worker characteristics and helps support simulations of marginal tax rates. They find subsidies are unevenly distributed. The average tax subsidy per worker is larger for bigger private employers, for those with a predominantly full-time workforce, and for those with a relatively higher paid workforce. The researchers project that the total federal and state subsidy in 2006 for ESI coverage of active workers will be $\$ 208.6$ billion or $\$ 2,788$ per covered worker.

\subsection{Retiree Provisions}

The surge in the number of Americans concerned with retirement benefits has only just begun with the first Baby Boomer filing for social security benefits in October 2007. According to the 2000 Decennial Census, more than 1 out of every 4 adults will be 
55 years of age or older by the year $2015{ }^{18}$ Health insurance coverage and expenses are a major financial concern for the growing numbers of both early retirees (55 to 64 years old) and Medicare-eligible retirees (65 years of age or older). A large percentage of each of these cohorts (67 percent and 36 percent, respectively) was covered by employersponsored retiree health insurance (RHI) in 2006 (see Figure 1). ${ }^{19}$

But, can retirees continue to rely upon employers as a source of insurance coverage? Rising premium costs, economic downturns, and Medicare-provided drug benefits have all been cited as reasons why employers may drop RHI. According to estimates using the MEPS-IC, the percent of private-sector establishments offering health insurance to current workers that also offer health insurance to retirees has hovered around 13 percent in recent years, dropping only a couple of percentage points since the late 1990s ${ }^{20}$ Concerns about ESI coverage for retirees have been studied at CES and the RDCs using the restricted-use MEPS-IC files. This survey provides advantages over other data sources on RHI because the MEPS-IC is conducted every year and samples establishments with one or more employees. RDC researchers have produced new estimates showing larger and older employers are more likely to offer RHI, a decline in RHI offers to new retirees, and an increase in retiree contributions towards premium costs.

Financial security in retirement can be threatened by high medical costs and is a particularly pertinent issue for older workers. Eibner et al. (2007) use the 2000-2004 MEPSIC to evaluate RHI access and RHI contribution requirements for this segment of the population by weighting each observation by the number of workers over the age of 50 employed at each establishment. They find no evidence of a significant decline from 2000 to 2004 in the probability of older workers being employed by private-sector establishments that provide RHI to existing retirees. The probability remained constant at about 27 percent for both early retirees (less than 65 years of age) and Medicare-eligible retirees (65 years of age or older). Beginning in 2001, the MEPS-IC has collected data on new retirees, asking additional questions about only those people retiring from the organization during the survey year. As shown in Figure 3, the probability that new retirees were eligible for RHI declined roughly 5 percentage points between 2001 and 2004. Additionally, this study shows retirees face increasing contribution requirements and increasing risk for having an "access-only" plan (i.e., employer offers group coverage plan but makes no contribution towards its premium cost). These findings raise concern about the cost of health insurance coverage for future retirees.

Measured at the establishment level, these overall trends show some differences when broken out by early retirees (under age 65) and Medicare-eligible retirees (65 and older). Zawacki (2006) shows that from 1997 to 2000, establishments that offer RHI are more likely to offer coverage to early retirees than to Medicare-eligible retirees. Similarly, from 2001 to 2003, establishments that offer RHI are more likely to offer coverage to new early retirees than to new Medicare-eligible retirees.

The relationship between trends in RHI offers and employer characteristics is also important to understand and has been studied by Buchmueller et al. (2006) and Zawacki

\footnotetext{
${ }^{18}$ U.S. Census Bureau, 2000. Projections of the Total Resident Population by 5-Year Age Groups and Sex With Special Age Categories: Middle Series, 2011 to 2015. National Population Projections, Summary Files (consistent with 1990 Census). <www.census.gov/population/projections/nation/summary/np-t3-d.txt>.

${ }^{19}$ DeNavas-Walt et al. (2007).

${ }^{20}$ Agency for Healthcare Research and Quality, Center for Financing, Access, and Cost Trends. 2002-2005 MEPS-IC.
} 
(2006) within the private sector from 1997 to 2003. Using the MEPS-IC, Buchmueller et al. find that larger employers and older firms are more likely to offer RHI, and these benefits are more likely to be made available to unionized workers and by employers with an older workforce. Similar to the findings by Eibner et al. (2007), these researchers also find that average total premiums for RHI have increased over time and the employee's share of the premium cost has risen.

Zawacki (2006) shows that businesses with fewer low-wage and part-time workers are more likely to offer RHI. In addition, there are some industry differences in the trends-for example, RHI offers by establishments in transportation/utilities and wholesale trade increased, but enrollment fell. Enrollments in family coverage declined at establishments with fewer female employees and increased at establishments with a greater proportion of low-wage workers. Further, Zawacki (2006) finds that the number of enrollees at unionized establishments has declined as enrollment in nonunionized establishments has increased. Explanations for these findings include the definition of unionization used by the author (i.e., an establishment is considered unionized if 25 percent or more of the workforce belongs to a union, thereby reducing the number of establishments considered unionized), the reduction in RHI benefits in renegotiated union contracts, or the shifts in employment to nonunionized establishments.

As Buchmueller et al. (2006) show, larger and older firms are more likely to offer RHI, and manufacturing firms are often larger and older than firms found in other industries. Restricting their sample to manufacturing, Born and Zawacki (2006) linked establishments from the 1999 MEPS-IC with the 1997 Census of Manufactures to study offers of RHI by firms. In the first stage of their analysis, the researchers also find that size (number of employees) and firm age increase the probability that a firm offers RHI. In the second stage, they examine the impact of the firm's financial performance and the availability of alternative insurance options available in the market on the percentage of the RHI premium cost contributed by the employer. The results indicate that these factors play a small but significant role in the proportion of the premium paid by firms.

\subsection{Institutional Framework}

The provision of ESI is not only motivated by productivity incentives, labor market conditions, or labor relations. The availability of this non-wage benefit is also affected by the institutional framework: the legal environment and insurance supply market an employer faces. The legal environment governs what is offered and to whom, while the group insurance market determines the types of plans available and cost to employers. As pressures from rising health care and insurance costs mount, employers and providers are looking for alternatives in the group insurance market. Consumers, concerned with rising costs but also access to quality care, press for more health care choices and a greater range of benefits. A number of papers by CES staff and RDC researchers provide insights on how employers and consumers have interacted within the evolving institutional framework over the last 20 years and how this has changed insurance coverage, insurance costs, types of plans, and benefits. Understanding how these groups have responded to past changes in the institutional framework will be very important in considering changes for the future. These studies have all used employer information on health benefits offerings and require data covering multiple years to examine the impact of changes in legal mandates, plan offerings, or market pressures. 
The MEPS-IC list sample, which can only be accessed via the secure Census Bureau environment, has been a particularly important source of consistent data covering more than 10 years.

Using the MEPS-IC list sample, Cooper, Simon, and Vistnes (2006) examine the decline in popularity of Health Maintenance Organizations (HMOs). The researchers analyze changes in enrollment in each of the four major ESI plan types between 1997 and 2003: HMOs, preferred-provider organizations (PPOs), fee-for-service (FFS), and pointof-service (POS) plans. They break down the enrollment changes into changes in employer plan offerings and employee choices among offered plans. The researchers find an overall decline in HMO enrollment (32 percent to 26 percent) similar to other studies, but their results indicate that the decline occurred post-2001 rather than in the late 1990s. Figure 4 shows the change in the percentage of enrollees in HMO plans compared to PPO plans estimated by Cooper et al. The percentage of enrollees in HMOs fell by 18 percent while the percentage in PPOs rose by 45 percent; about half of enrollees were in PPO plans in 2003 while only a quarter were enrolled in HMOs. Small to medium-sized employers (less than 1,000 employees) increasingly offered HMOs, but large employers reduced HMO offerings and their employees were less likely to choose HMOs over other plans. PPOs showed a 15 percentage-point rise in enrollment because, in firms of all sizes, employers were more likely to offer PPOs and when offered, employees increasingly chose them.

Regulations related to the sale of health insurance, particularly at the state level, are another important feature of the environment affecting ESI. In recent years, state legislatures have moved to enact regulations either to encourage more employers to provide health insurance, to increase the range of benefits covered, and/or to reduce the impact that worker characteristics have on the price or availability of health insurance. Smaller employers are much less likely to offer health insurance; one potential reason for this is that smaller employers may face highly variable premium costs from one year to the next as worker insurance claims vary. ${ }^{21}$ Simon (2005) uses the MEPS-IC list sample to examine states that implemented reforms in the early 1990s aimed at increasing ESI offers at small employers. The reforms limited the degree to which insurers could price discriminate between low- and high-risk customers and, in some states, created guaranteed issue laws. Simon compares changes between 1992 and 1996 in benefit offerings (premiums, employee contributions, and employer offers of health insurance) and the coverage rate at small employers in reform states with two control groups: large employers in reform states and small employers in nonreform states. Since the MEPSIC's first year of coverage was calendar year 1996, Simon used an innovative approach to combine the MEPS-IC estimation results with another restricted-access dataset, the 1993 National Employer Health Insurance Survey. Results indicate that reforms increased monthly premiums by a significant $\$ 7.80$ and employee contributions by $\$ 5.10$. No effect was found on offers of health insurance, but the rate of enrollment fell by two percentage points. Simon indicates that the reforms' failure to increase coverage at small employers is not surprising. The results are in line with a prediction of economic models that when insurers cannot differentiate between risk groups, insurance can fall for healthier individuals but not for those with greater health care costs.

\footnotetext{
${ }^{21}$ For example, Zawacki and Taylor (2006) show that in 2001, less than half of small employers (less than 10 employees) offered health insurance compared to more than 90 percent of establishments with 100 or more employees.
} 
Buchmueller et al. (2007) examine another set of state-level reforms sought by mental health advocates - laws which mandated that plans not restrict coverage for mental health benefits more than other types of care. After the enactment of the 1996 Federal Mental Health Parity Act (MHPA), mental health advocates were concerned that MHPA did not do enough to increase availability of mental health benefits and pressed states to enact laws to increase their provision. The cost of such mandated benefits to firms is of concern; however, small employers were usually exempt from the reforms, and the federal Employee Retirement Income Security Act (ERISA) holds self-insured plans exempt from any state mandates. Buchmueller et al. use MEPS-IC data on enrollees, firm size, and plan type (e.g., self-insured) and state laws regarding adoption of reforms and find that the percentage of employees covered by ESI at firms required to expand mental health benefits increased from under 5 percent to about 20 percent between 1997 and 2002. Had small firms and firms subject to ERISA not been exempt from the mandate, the percentage of employees enrolled in ESI plans required to expand such benefits would be more than 40 percent. ESI at firms subject to ERISA accounts for the majority of the difference. Since such a large number of plans fall under the ERISA exemption, the researchers conclude that reforms aimed at expanding coverage for certain health conditions will have a limited effect if not done at the federal level.

Another important institutional feature of ESI is that in exchange for taxadvantaged treatment of health benefits, many large employers are subject to nondiscrimination (ND) rules. ${ }^{22}$ ND rules prevent firms from offering greater nonwage benefits, such as health insurance, to highly compensated individuals. However, different benefits can be offered for workers in distinct groups for business reasons (e.g., part-time vs. full-time, above/below 2 years of service). Carrington, McCue, and Pierce (2002) use the Bureau of Labor Statistics' Employer Cost Index survey to examine the effect of ND rules - whether they bind, increase, or decrease wage inequality within firms and affect how employees are grouped. The researchers find that ND rules reduce within-firm inequality in benefits and appear to increase use of benefits such as health insurance. ND rules also increase within-firm wage inequality and thus, have an ambiguous net effect on total compensation. The results also suggest that employees who are paid very differently (low wage at high-wage firms) are more likely to be part-time, a categorization that would enable firms to offer these workers a lower level of benefits.

\section{PUBLIC INSURANCE PROGRAMS}

Over the last several years, efforts have been made at the state and national level to address the health insurance needs of people with little or no access to private coverage. This includes both efforts to increase enrollment in public health insurance programs among eligibles and to extend eligibility to certain groups (children, households in poverty). As Figure 1 shows, public health insurance provides coverage for most adults aged 65 and over and, following several years of expansions in the Medicaid program, about a quarter of all children. ${ }^{23}$ For adults aged 18 to 64, public programs cover 10 to 16 percent of the population. Researchers, service providers, and

\footnotetext{
${ }^{22}$ These rules apply to employers who self-insure (assume financial risk for their plan); employers with self-insured plans are much larger than those who do not self-insure.

${ }^{23}$ People covered by military plans are not included in the discussion of public programs here.
} 
governments rely on survey estimates of those reporting public health insurance program coverage to assess the degree to which eligible individuals take up coverage and to obtain better estimates of the number and percentage of the uninsured. However, the estimates of Medicaid coverage in the CPS are markedly lower than estimates from administrative Medicaid data. ${ }^{24}$ Survey data have also been used to analyze the impact of expansions in Medicaid and the State Children's Health Insurance Program (SCHIP). Researchers have used Census Bureau RDC data to examine the accuracy of measures of public health insurance coverage and the uninsured population, as well as the impact of coverage expansions on employer offers of ESI.

The SCHIP expansions raised concern among policymakers that, in response to new SCHIP access, parents would drop private insurance and/or employers might change their dependent coverage offerings. Buchmueller, Cooper, Simon, and Vistnes (2005) study these questions in the MEPS-IC list sample, which, unlike studies based on household surveys, can directly examine mechanisms for substitutions between private and public coverage because it contains information from employers on plan offerings. The study finds no evidence that employers reduced offers of health insurance or coverage to dependents as more families had access to SCHIP for their children. However, at businesses with a high proportion of employees likely to be SCHIP eligible, the annual cost of family coverage (relative to single coverage) increased by approximately \$119 where 20 percent of the workforce was potentially eligible for public coverage and \$351 where 50 percent were potentially eligible. In take-up models for family coverage, the researchers find that these increases in employee contributions resulted in significant declines in family coverage enrollment of 1.4 and 4.6 percentage points, respectively, for these two groups.

Papers by Klerman and Ringel (2005) and Klerman, Ringel, and Roth (2005) analyze underreporting of Medicaid participation (Medi-Cal for the state of California) in the CPS and discuss its causes and effects. The project was able to match monthly data from California's Medi-Cal Eligibility Data System (MEDS) to responses in the Annual Social and Economic Supplement to the Current Population Survey (CPS ASEC) (March supplement) to examine these issues. ${ }^{25}$ The combined survey and administrative records data could only be used in the secure environment at the Census Bureau.

Klerman, Ringel, and Roth find that the CPS understates Medi-Cal enrollment by 30 percent for adults and 25 percent for children in the 1990s. Underreporting of welfare receipt (which confers automatic Medicaid eligibility) and thus, inferred Medi-Cal coverage is even greater-on the order of 50 percent. Effects differ by group-those with characteristics less associated with Medi-Cal or welfare receipt (higher income, more education, other health insurance during year) were more likely to underreport. Underreporting of participation also leads to overestimation of the number of the uninsured. This is of particular concern because estimates of the uninsured and program participation from the CPS are the official data source used to allocate SCHIP funding. The researchers develop methods that can be used to adjust the survey data to get more accurate measures of Medi-Cal participation and the uninsured. Figure 5 shows that the adjustments to the March CPS data for 1990-2000 used by Klerman et al. increase

\footnotetext{
${ }^{24}$ See Appendix C in DeNavas-Walt et al. (2007).

${ }^{25}$ The Census Bureau provided anonymized identifiers for both datasets, which allowed the researchers to perform the match.
} 
estimated Medi-Cal enrollment rates for adults and children by 4 and 9 percentage points respectively while lowering the estimated proportion of uninsured adults from 24 percent to 21 percent and uninsured children from 18 percent to 12 percent.

The CPS measures of health insurance are designed to ask about coverage at any point in the prior year. Research suggests there is underreporting in the CPS compared to other estimates of health insurance coverage, and one potential explanation is that respondents are answering the question as if it were asking about coverage at a point in time. ${ }^{26}$ Klerman and Ringel (2005) focus on this issue with respect to reports of MediCal receipt. The project compares the degree of false negatives and false positives, as well as how reporting varies by length of coverage in the administrative data. Their results indicate that respondent error in interpreting the period for reporting coverage accounts for less than half of the underreporting. In fact, the results suggest that the underreporting is more likely due to a reluctance to report coverage and the fact that the number of months of coverage appears to be positively correlated with reporting coverage in the CPS. Those with fewer months of coverage were less likely to report being covered even though the administrative data indicate that they were covered at a point in time.

Card, Hildreth, and Shore-Sheppard (2004) also used California administrative data on Medicaid enrollment to assess underreporting of Medicaid coverage in the SIPP. The researchers examine each data source separately for patterns of error, and then examine correspondence between the confidential matched survey and administrative reports. The researchers find spikes in changes in Medicaid coverage at the beginning and end of the month and in the month immediately prior to the interview-or seam bias - in the SIPP data. Card et al. also find seam bias in the administrative data, which could result from missing social security numbers (SSNs) on initial application files that were filled in later. The researchers exploit overlap in the administrative records (that include eligibility in the current month and at any time in the prior 15 months) and find inconsistencies in the administrative reports, most likely because people can be deemed eligible after seeking care. In the matched sample, the coverage reported in the SIPP actually exceeds that reported in the administrative data. If the administrative data are assumed to be correct, then unmatched SIPP recipients (those without a valid or reported SSN) would have to underreport Medicaid participation at a very high rate to generate the aggregate level of underreporting. Once problems with SSNs and other errors in the administrative data are accounted for, the researchers estimate that the degree of underreporting in the survey data is not large-85 percent of the overall Medi-Cal population and more than 90 percent of children with Medi-Cal report coverage in the SIPP. The researchers conclude that errors in reported SIPP Medicaid status will not greatly attenuate estimated effects of Medicaid as either an explanatory or dependent variable in regression models. At most, reporting errors could produce a 20 percent reduction in the estimated impact of Medi-Cal as an explanatory variable.

\section{INDIVIDUAL HEALTH INSURANCE MARKET}

According to the 2006 Current Population Survey (CPS), the employer-sponsored insurance market provided coverage for almost 60 percent of the population, and public

\footnotetext{
${ }^{26}$ See Klerman and Ringel (2005).
} 
insurance provided coverage for 27 percent; meanwhile almost 16 percent are uninsured. $^{27,28}$ Figure 6 shows the percentage of the population at all ages that is uninsured. The employer-sponsored and individual insurance markets are two sources of private coverage, and the latter covered approximately 9.1 percent of the population in 2006 according to the CPS. ${ }^{29}$ In this market, individuals purchase a health plan directly from a private insurance company rather than obtaining coverage through a group, such as their employer. Some discussions consider whether the individual market may be a viable source of coverage for the uninsured. Affordability is considered to be one reason why people do not have insurance. Tax credits and subsidies have therefore been proposed to reduce the cost of coverage in the individual market. Aside from affordability, coverage for the chronically ill or those with preexisting conditions may also present issues. These medical conditions may be excluded from health insurance plans obtained in the individual market, although this market may provide greater health plan choice than what is available from employers. Researchers using confidential RDC data, which allowed them to use variations of combined data from households, insurers, and employers, have produced new estimates on the individual insurance market. Using this improved data, the studies show that subsidies in the individual market only modestly increase the rate that plans are bought, reduce the number of uninsured families by only a small percentage, and may not be efficient for promoting whole family coverage. The research also finds, however, that people with health problems do in fact obtain individual coverage.

A group of RDC researchers have studied the individual insurance market in California. These studies use various combinations of demographic data from the Census Bureau (including the CPS and SIPP) and external data sources (including the National Health Interview Survey, Robert Wood Johnson Employer Health Insurance Survey, administrative data from insurers, and data on California health care markets including the researchers' own surveys of individuals). Their publications from 2004 through 2007 examine the impact of subsidies, product design, and consumer decision-making in the individual insurance market. California is the focus because the researchers were able to obtain data on the premiums and benefit offerings for the majority of individual health plans in this market. The authors also point out that while the analyses are limited to one state, California is a large state with variation in premium costs within the state. And, like other states, California has few regulations in the individual market. California also experienced a change in plan offerings during the period studied, and California's trends in employer-sponsored insurance and uninsurance reflect national trends. On the other hand, in California's individual insurance markets HMOs are more prevalent, and premiums in its individual market tend to be lower than national averages.

Marquis, Buntin, Escarce, Kapur, and Yegian (2004) study two decisions related to the individual insurance market using a combination of the data described above. First, they estimate the probability that a family would purchase coverage in the individual market if the family lacked access to group coverage. Even a subsidy of 50 percent would reduce the number of uninsured families by only about 4 to 8 percent.

\footnotetext{
${ }^{27}$ Here, “public insurance” includes Medicare, Medicaid, and military health care.

${ }^{28}$ See DeNavas-Walt et al. (2007) and footnotes 10 and 17.

${ }^{29}$ Individuals may receive coverage from more than one source; therefore, the total percent insured is 84 percent and not simply the sum of the percent covered by the employer, public, and individual markets.
} 
Second, they study the decision to purchase group insurance, individual insurance, or to remain uninsured by workers who are offered group coverage. Few individuals with access to employer-sponsored group coverage are likely to switch to individual coverage if offered a subsidy, indicating that offering subsidies in the individual market would not necessarily translate into the crumbling of the employer-based system.

Data from California are again used by Marquis et al. (2006) to examine risk pooling in the individual market. This work found that many people with health problems do in fact obtain individual insurance - almost one-third of purchasers report having an adult family member with at least one chronic condition. People in poor health at enrollment do pay higher prices than healthy people, but the differences are not large —on the order of 10 percent. This suggests that insurers pool risks to some extent-that is, they spread risks across purchasers rather than charge much higher premiums for those in poor health. Despite the fact that consumers in poorer health do get access to individual health insurance, Marquis et al. (2006) show that consumers in poorer health are less likely to enroll in the individual market than those in better health, even when controlling for preferences and income. Highrisk subscribers are less likely to purchase high-deductible plans. Also, more than 30 percent of new episodes of coverage in the individual market maintain the coverage for more than 3 years and older subscribers are more likely to use the individual market for long-term coverage.

To focus their analyses on individuals who are most likely to purchase products in the individual insurance market, Marquis et al. (2007) use a sample of families from California who lack access to group coverage and are not enrolled in public insurance. Product choice appears sensitive to price, while decreases in deductibles and out-ofpocket maximums will only modestly increase participation. The authors show that a 50 percent subsidy to families in this sample would decrease the number of uninsured by only about 3 percent. The findings again suggest the importance of addressing nonprice barriers. Marquis et al. suggest that introducing new high-deductible plans is unlikely to significantly reduce the number of uninsured. They point out, however, that they do not have data to study the impact of high-deductible plans when used in combination with health savings accounts.

Some families are only partially insured, which means that one or more of the adults and/or children in the family are not covered by insurance. This can result in adverse consequences for both the insured and uninsured members of the family. Kapur et al. (2007) study increasing whole family coverage through the use of subsidies in the individual insurance market. The authors focus on three options: (1) purchase individual health insurance and cover the entire family; (2) purchase individual health insurance, leaving some or all of the children uninsured; or (3) purchase individual coverage but leave only the adults uninsured. Premium subsidies for individual insurance would increase whole family coverage and reduce the number of partially uninsured families among those who purchase individual coverage. The role of the subsidies would be small, however, because efficiently targeting subsidies to this population is difficult. 


\section{REFERENCES}

Angrist, Joshua D. and Stacey H. Chen. 2007. "Long-Term Effects of Vietnam-Era Conscription: Schooling, Experience, and Earnings.” Center for Economic Studies Discussion Paper CES-07-23.

Born, Patricia H. and Alice M. Zawacki. 2006. "Manufacturing Firms’ Decisions Regarding Retiree Health Insurance.” Benefits Quarterly, 22(1): 34-44.

Buchmueller, Thomas, Philip Cooper, Kosali Simon and Jessica Vistnes. 2005. "The Effect of SCHIP Expansions on Health Insurance Decisions by Employers.” Inquiry, 42(3): 218-31.

Buchmueller, Thomas, Philip Cooper, Mireille Jacobson, and Sam Zuvekas. 2007. "Parity for Whom? Exemptions and the Extent of State Mental Health Parity Legislation." Health Affairs, 26(4): 483-487.

Buchmueller, Thomas, Richard W. Johnson, and Anthony T. LoSasso. 2006. "Trends in Retiree Health Insurance, 1997-2003.” Health Affairs, 25(6): 1507-16.

Card, David, Andrew K.G. Hildreth, and Lara D. Shore-Sheppard. 2004. "The Measurement of Medicaid Coverage in the SIPP: Evidence From a Comparison of Matched Records.” Journal of Business and Economic Statistics, 22(4): 410-20.

Carrington, William, Kristin McCue, and Brooks Pierce. 2002. "Nondiscrimination Rules and the Distribution of Fringe Benefits.” Journal of Labor Economics, 20(2): S5-33.

Centers for Medicare and Medicaid Services, Office of the Actuary, National Health Statistics Group.

$<$ www.cms.hhs.gov/NationalHealthExpendData/02_NationalHealthAccountsHistoric al.asp>.

Cooper, Philip F. and Jessica P. Vistnes. 2003. “Worker's Decisions to Take-Up Offered Health Insurance Coverage: Assessing the Importance of Out-of-Pocket Premium Costs.” Medical Care, 41(7): III-35-III-43.

Cooper, Philip F., Alison P. Hagy, and Jessica P. Vistnes. 1999. “The Medical Expenditure Panel Survey: Creation of a Linked Employer-Employee Database.” In The Creation and Analysis of Employer-Employee Matched Data, ed. John Haltiwanger, Julia Lane, James Spletzer, Jules Theeuwes, and Kenneth Troske, 553-68. Amsterdam: Elsevier Science.

Cooper, Philip F., Kosali Simon, and Jessica Vistnes. 2006. “A Closer Look at the Managed Care Backlash.” Medical Care, 44(5): 4-11.

Decressin, Anja, Kristin McCue, and Martha Stinson. 2003. "Describing the Form 5500Business Register Match.” Longitudinal Employer-Household Dynamics Technical Paper TP-2003-05.

Decressin, Anja, Julia Lane, Kristin McCue, and Martha Stinson. 2005. "Employer-Provided Benefit Plans, Workforce Composition, and Firm Outcomes.” Longitudinal Employer-Household Dynamics Technical Paper TP-2005-01. 
Decressin, Anja, Tomeka Hill, Kristin McCue, and Martha Stinson. Forthcoming. "The Role of Fringe Benefits in Employer and Workforce Dynamics.” In Producer Dynamics: New Evidence From Micro Data, ed. Timothy Dunne, J. Bradford Jensen, and Mark J. Roberts. Chicago, IL: University of Chicago Press.

DeNavas-Walt, Carmen, Bernadette D. Proctor, and Jessica Smith. 2007. "Income, Poverty, and Health Insurance Coverage in the United States: 2006.” Current Population Reports, P60-233, U.S. Census Bureau, Washington, DC.

Eibner, Christine, Alice M. Zawacki, and Elaine M. Zimmerman. 2007. “Older Workers' Access to Employment-Sponsored Retiree Health Insurance, 2000-2004.” Center for Economic Studies Discussion Paper Series CES-07-12.

Gabel, Jon, Roland McDevitt, Laura Gandolfo, Jeremy Pickreign, Samantha Hawkins, and Cheryl Fahlman. 2006. "Generosity and Adjusted Premiums in Job-Based Insurance: Hawaii Is Up, Wyoming Is Down.” Health Affairs 25(3): 832-43.

Houtenville, Andrew J. and William A. Erickson. 2007. "Complex Survey Questions and the Impact of Different Enumeration Procedures: Census/ACS Disability Items.” Presented at the 2007 CES and RDC Annual Research Conference, U.S. Census Bureau, Suitland, MD.

Kapur, Kanika, Jose Escarce, and Susan Marquis. 2007. "Individual Health Insurance Within the Family: Can Subsidies Promote Family Coverage?" Inquiry, 44(3): 303-320.

Klerman, Jacob Alex, Jeanne S. Ringel, and Beth Roth. 2005. "Under-Reporting of Medicaid and Welfare in the Current Population Survey.” RAND Labor and Population Working Paper WR-169-3.

Marquis, M. Susan, Melinda Beeuwkes Buntin, Jose Escarce, and Kanika Kapur. 2007. "The Role of Product Design in Consumers' Choices in the Individual Insurance Market." Health Services Research, 42(6p1): 2194-223.

Marquis, M. Susan, Melinda Beeuwkes Buntin, Jose Escarce, Kanika Kapur, and Jill Yegian. 2004. "Subsidies and the Demand for Individual Health Insurance in California." Health Services Research, 39(5): 1547-70.

Marquis, M. Susan, Melinda Beeuwkes Buntin, Jose Escarce, Kanika Kapur, Thomas A. Louis, and Jill Yegian. 2006. "Consumer Decision Making in the Individual Health Insurance Market.” Health Affairs, 25(3): 226-34.

McCue, Kristin and Alice Zawacki. 2006. "Using Census Business Data to Augment the MEPS-IC.” Journal of Economic and Social Measurement, 31(1): 47-67.

Ringel, Jeanne S. and Jacob Alex Klerman. 2005. “Today or Last Year? How Do Interviewees Answer the CPS

Health Insurance Questions?” RAND Labor and Population Working Paper WR-288.

Selden, Thomas M. and Bradley M. Gray. 2006. "Tax Subsidies for Employment-Related Health Insurance: Estimates for 2006.” Health Affairs, 25(6): 1568-79.

Simon, Kosali Ilayperuma. 2005. "Adverse Selection in Health Insurance Markets? Evidence From State Small-Group Health Insurance Reforms.” Journal of Public Economics, 89: 1865-77. 
Stern, Sharon M. 2003. "Counting People With Disabilities: How Survey Methodology Influences Estimates in Census 2000 and the Census 2000 Supplementary Survey,” Proceedings from 2003 Joint Statistical Meetings, (May): 4064-4071.

Stern, Sharon M. and Matthew Brault. 2005. "Disability Data From the American Community Survey: A Brief Examination of the Effects of a Question Redesign in 2003.” Census Bureau Working Paper, January 28, 2005.

Vistnes, Jessica P., Philip F. Cooper, and Gregory S. Vistnes. 2001. "Employer Contribution Methods and Health Insurance Premiums: Does Managed Competition Work?" International Journal of Health Care Finance and Economics, 1: 159-87.

Vistnes, Jessica Primoff, Michael A. Morrisey, and Gail A. Jensen. 2006. "Employer Choices of Family Premium Sharing." International Journal of Health Care Finance and Economics, 6: 25-47.

Zawacki, Alice. 2006. "Using the MEPS-IC to Study Retiree Health Insurance.” Center for Economic Studies Discussion Paper CES-06-13.

Zawacki, Alice and Amy Taylor. 2005. "Contributions to Health Insurance Premiums: When Does the Employer Pay 100\%?” Center for Economic Studies Discussion Paper CES05-27. 
Figure 1. Source of Insurance Coverage by Age Category

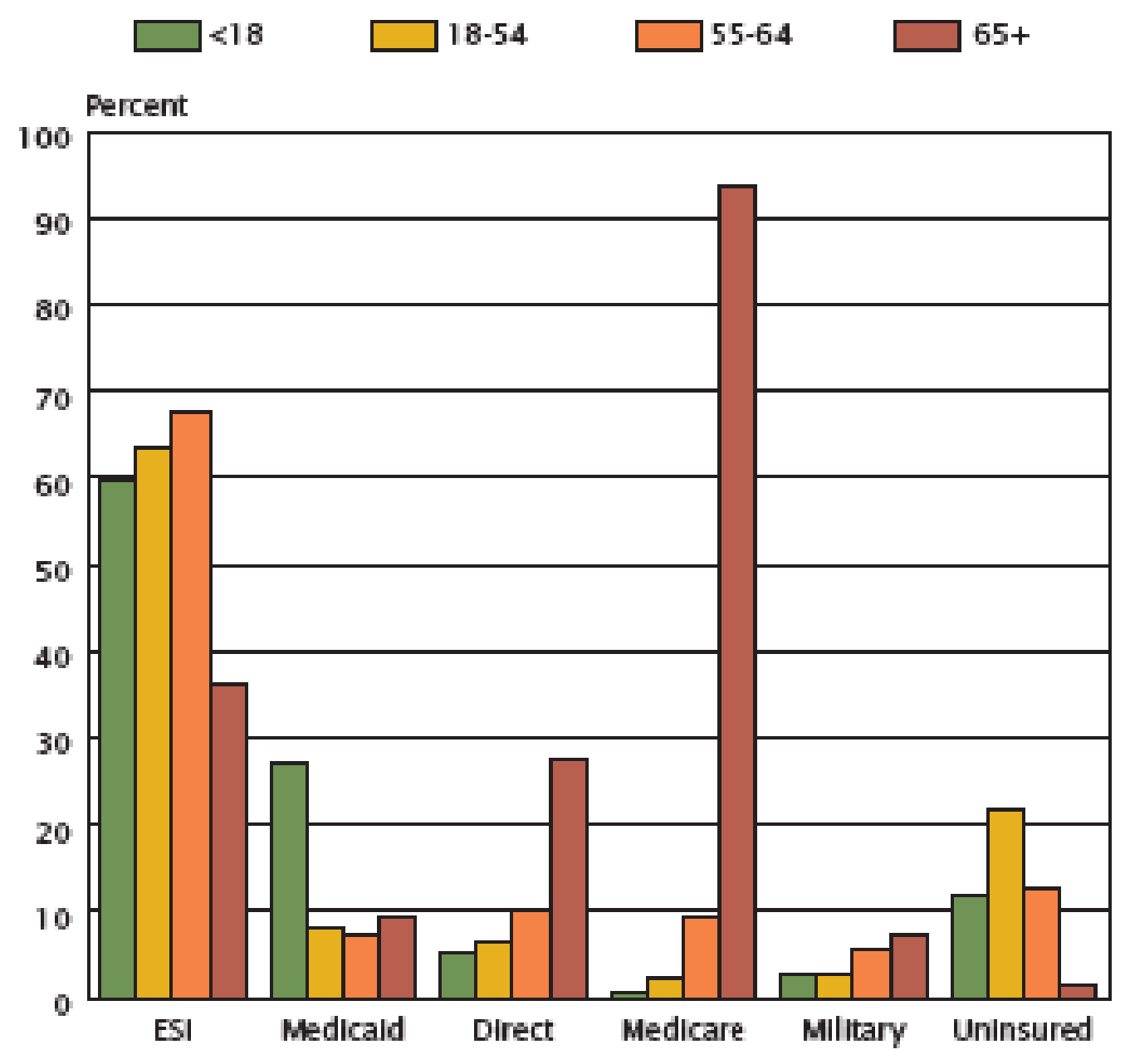

Source: Dellaws: Whatt, Protor, and Smith, 2007. 
Figure 2. Percent of Establishments Offering Insurance That Pay 100 Percent of Premium for at Least One Plan

$\begin{array}{llll}\square \text { offers 1 } & \square \text { offers 1 } & \square \text { offers }>1 & \square \text { offers }>1 \\ \text { plan and } & \text { plan and } & \text { plan and } & \text { plan and } \\ \text { pays 100\% } & \text { pays 100 } & \text { pays } 100 \% & \text { pays 100\% } \\ \text { for single } & \text { for famly } & \text { for single } & \text { for famlly } \\ \text { coverage } & \text { coverage } & \text { coverage } & \text { coverage } \\ & & \text { for at least } & \text { for at least } \\ & & \text { one plan } & \text { one plan }\end{array}$

Percent of establishments offering Insurance

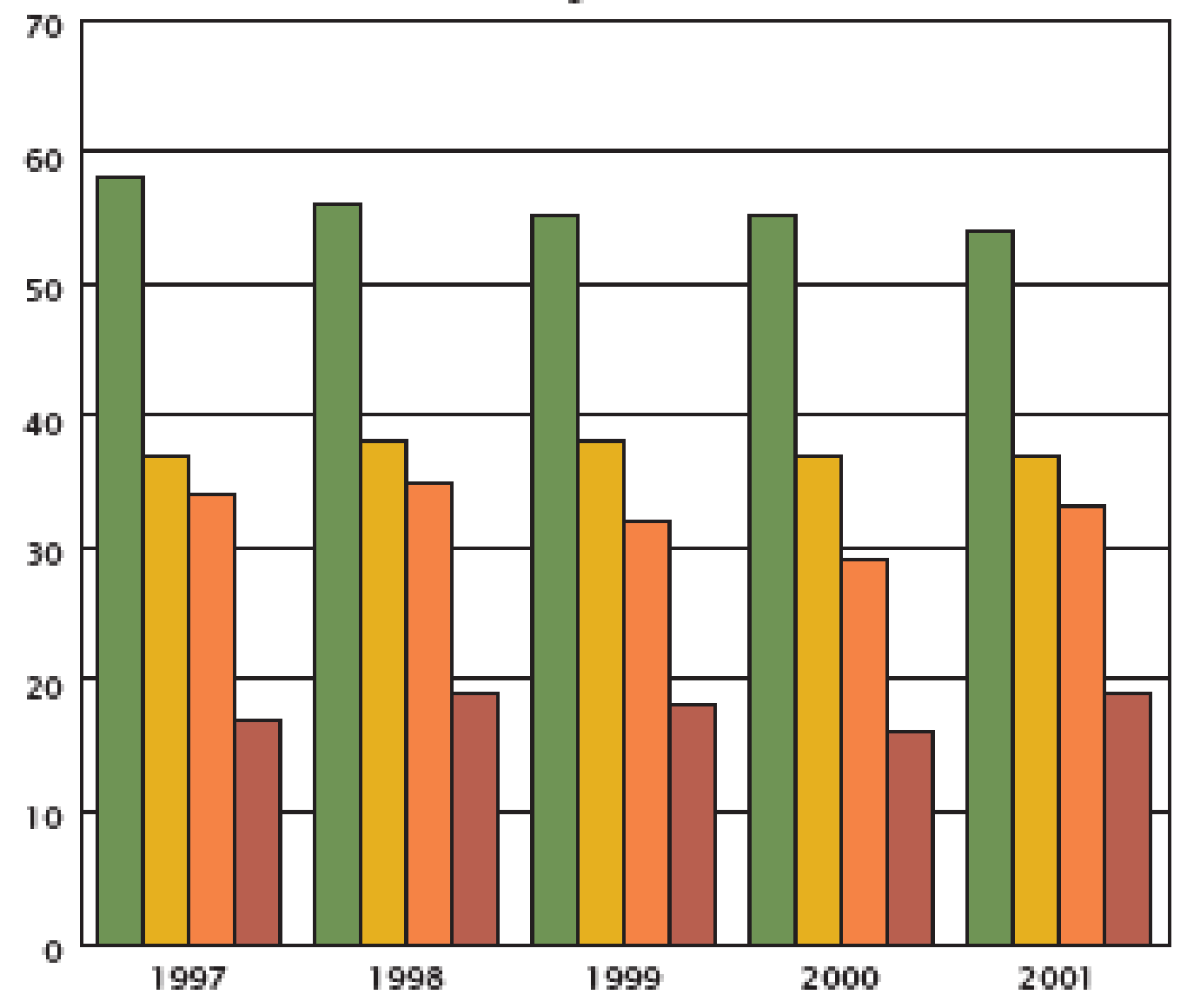

Source: Zawacki and Taylor, 2005. 
Figure 3. Probability That Workers Age 50+ Are at Businesses Offering Insurance to New Retirees (Percent)
$\square$ Establishment offers Insurance to new retlres $<65^{*}$

Establishment offers Insurance to new retlrees $65+^{*}$

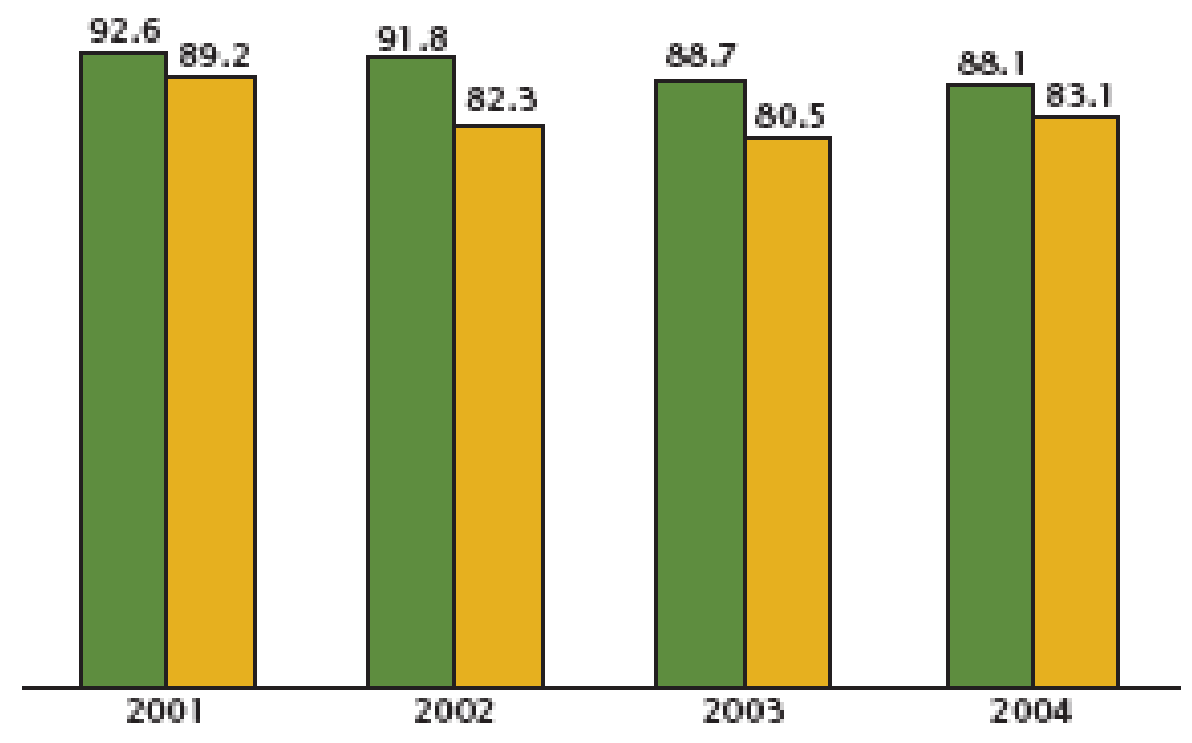

"Conditional on halth insurance prosision to sxisting retireses 65 and 65 t, reapectimaly. Source: Eibnar, Zawacki, and Zimmarman, 2007. 
Figure 4. Percentage of Enrollees in HMOs and PPOs: 1997 and 2003

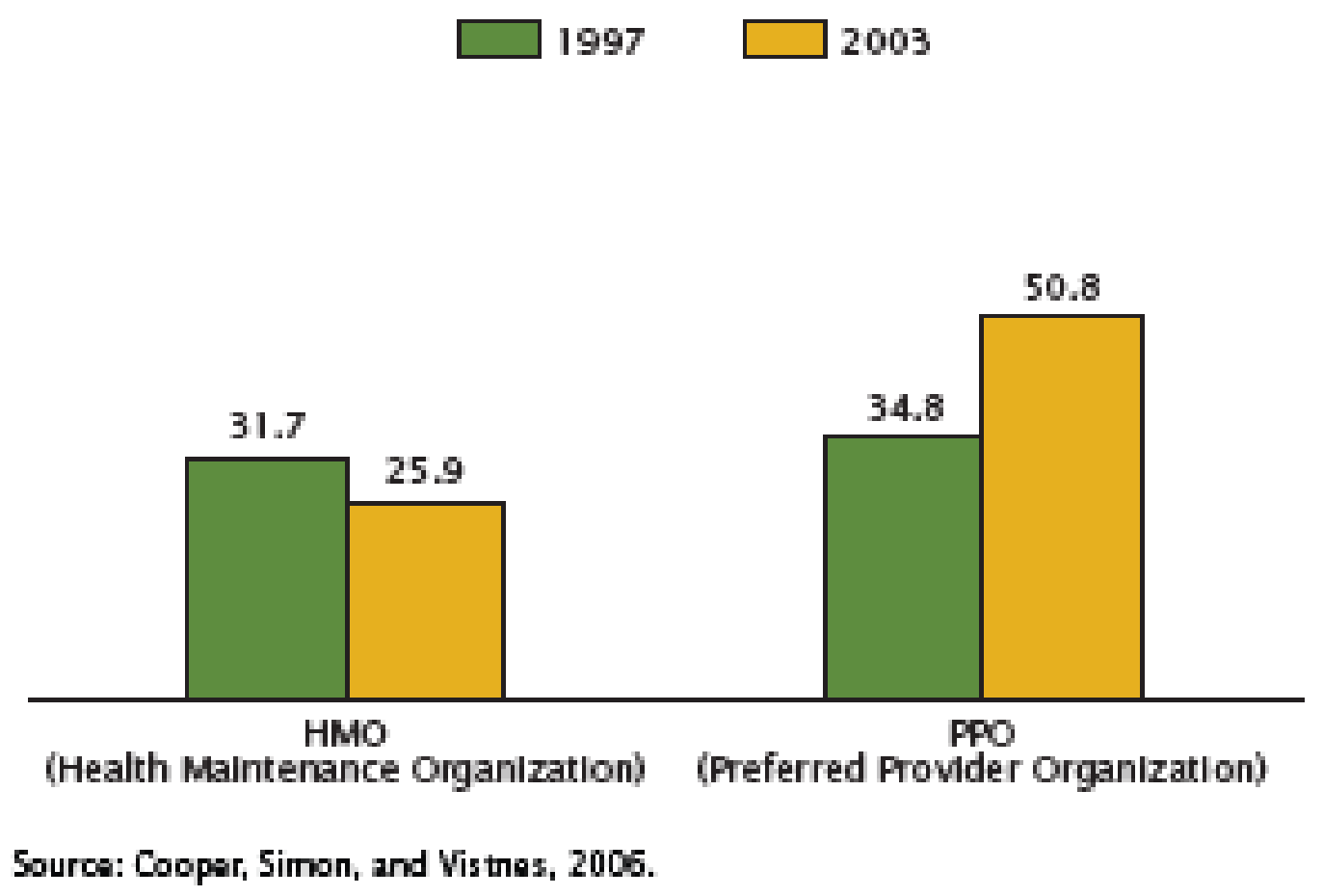


Figure 5. Adjusted CPS Rates for Medicaid Enrollment and Percentage Uninsured (Data for California, Current Population Survey, 1990-2000)
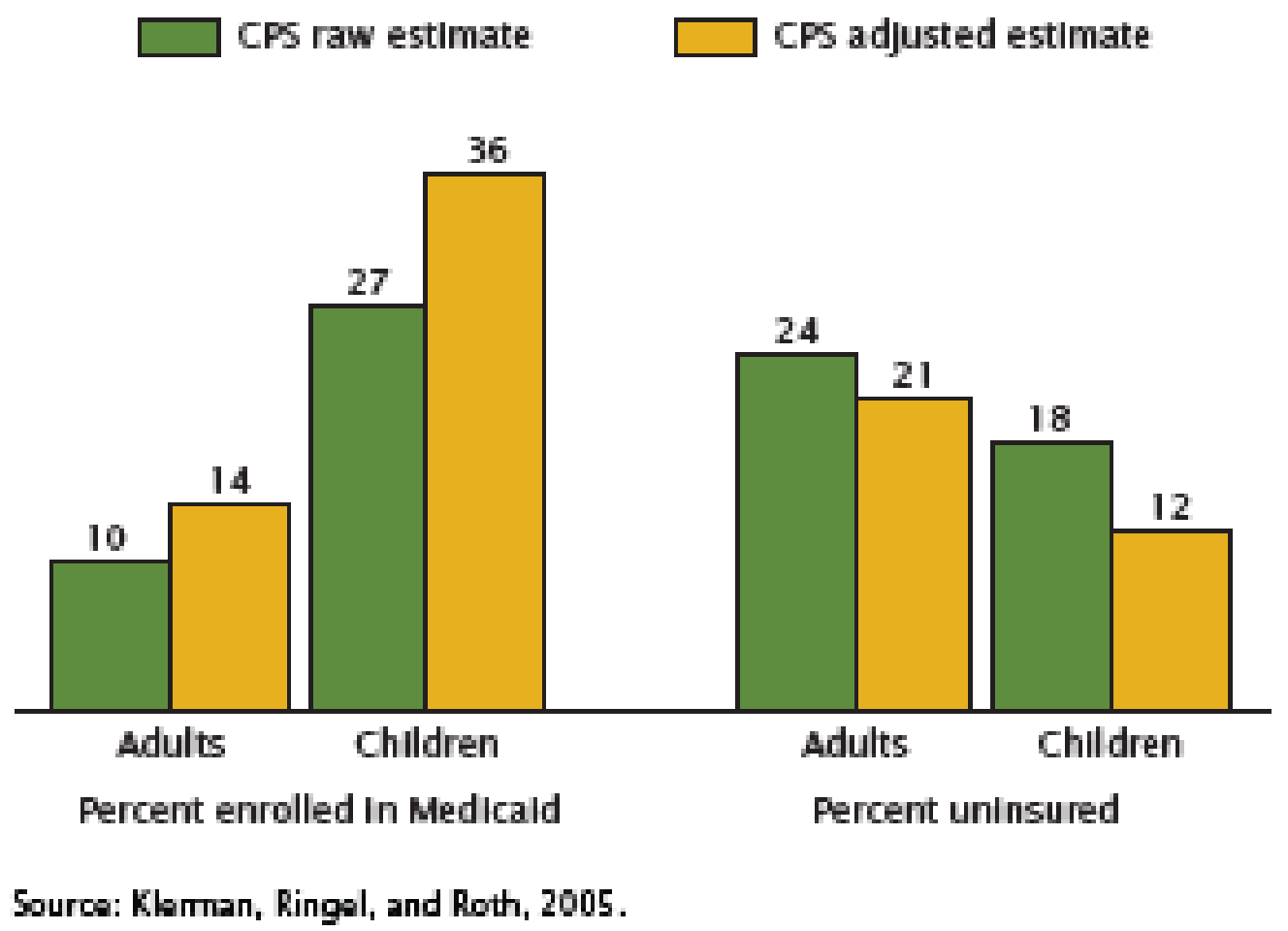
Figure 6. Health Insurance Coverage: 2006

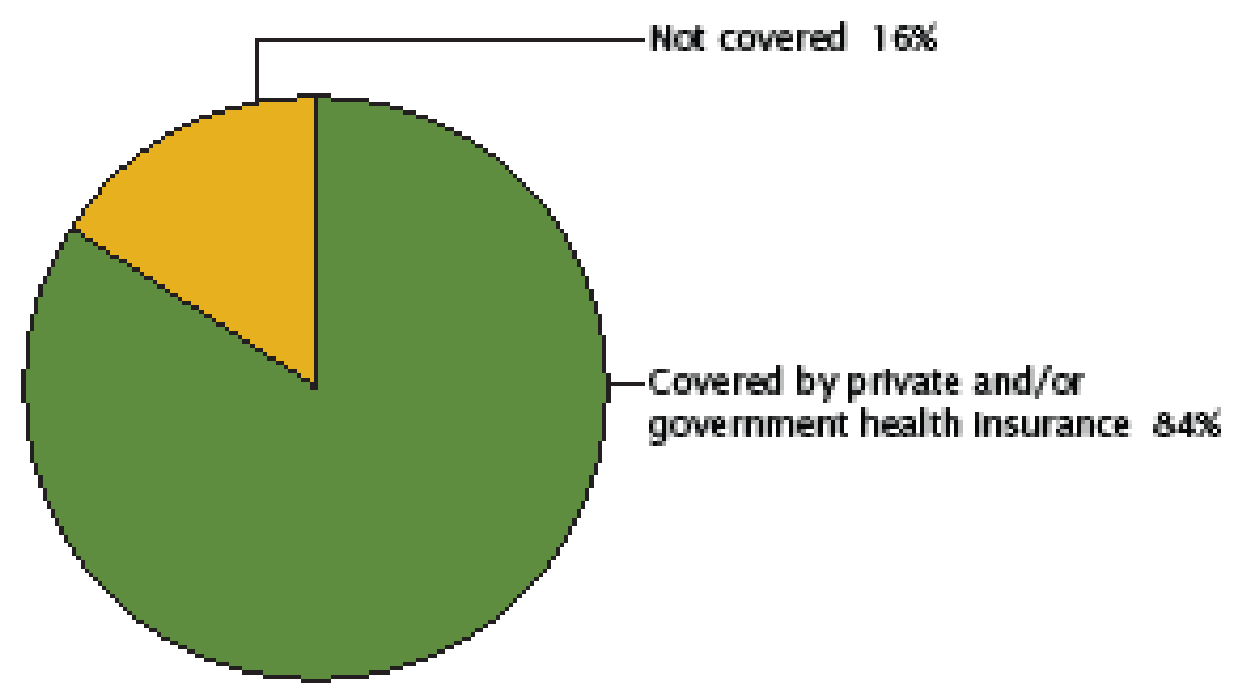

Sourca: DoNuas-halt, Proctor, and Smith, 2007. 